\title{
Occurrence of Highly Resistant Microorganisms in Ruai Wastewater Treatment Plant and Dandora Dumpsite in Nairobi County, Kenya
}

\author{
Edinah Song'oro ${ }^{1,2}$, Andrew Nyerere², Gabriel Magoma1,2, Revathi Gunturu ${ }^{3}$ \\ ${ }^{1}$ Pan African University Institute for Basic Sciences Technology and Innovation (PAUSTI), Nairobi, Kenya \\ ${ }_{2}^{2}$ Jomo Kenyatta University of Agriculture and Technology (JKUAT), Nairobi, Kenya \\ ${ }^{3}$ The Aga Khan University Hospital (AKUH), Nairobi, Kenya \\ Email: edinahsong@gmail.com
}

How to cite this paper: Song'oro, E., Nyerere, A., Magoma, G. and Gunturu, R. (2019) Occurrence of Highly Resistant Microorganisms in Ruai Wastewater Treatment Plant and Dandora Dumpsite in Nairobi County, Kenya. Advances in Microbiology, 9, 479-494. https://doi.org/10.4236/aim.2019.95029

Received: March 9, 2019

Accepted: May 19, 2019

Published: May 22, 2019

Copyright $\odot 2019$ by author(s) and Scientific Research Publishing Inc. This work is licensed under the Creative Commons Attribution International License (CC BY 4.0).

http://creativecommons.org/licenses/by/4.0/

(c) (i) Open Access

\begin{abstract}
Wastewater treatment plants and solid dump sites act as potential reservoirs of highly resistant bacterial strains. This study presents information on the patterns of antimicrobial resistance among pathogenic bacteria in the sewage treatment plants and solid dump site in Nairobi County, Kenya. We employed standard microbiological methods to isolate and identify bacteria from these selected sites. Members of Escherichia, Klebsiella, Serratia, Shigella, Pseudomonas, Citrobacter spp, Enterobacter, Salmonella, Staphylococcus, Bacillus, Yersinia, Vibro cholera, Providencia, Morganella and Proteus spp were isolated. Escherichia and Klebsiella recorded the highest occurrence at $13.9 \%$ and $10.3 \%$ in wastewater. Shigella, Serratia Citrobacterfreundii, Pseudomonas, Staphylococcus, Escherichia and Klebsiella recorded the highest level of occurrence at $15.1 \%, 14.1 \%, 12 \%, 11 \%, 10.4 \%, 10.3 \%$, and $8.3 \%$ in dumpsite respectively. Drug sensitivity using the Disc diffusion method showed that Ampicillin, Ceftazidime, Cefotaxime, Amoxicillin, and Cefepime had the highest levels of inactivity at $(68.5 \%, 89.5 \%),(64.2 \%, 87 \%),(54.5 \%$, $80.2 \%),(52 \%, 74 \%)$ and $(49.1 \%, 72.4 \%)$ respectively while Levofloxacin and Gentamicin showed the smallest level of antibiotic resistance at $(4.8 \%, 4.7 \%)$ and $(4.2 \%, 2.6 \%)$ in both sites. Members of Escherichia, Klebsiella, Proteus vulgaris, Salmonella, Pseudomonas, Shigella and Serratia showed the highest level of ESBLs production at 28.9\%, 18.4\%, 15.8\%, 10.5\%, 7.9\%, 7.9\%, 7.9\% and $7.9 \%$ in the wastewater whereas Shigella, Escherichia, Serratia, Pseudomonas, Klebsiella, and Proteus vulgaris showed the highest level ESBLs production at $45.5 \%, 10.9 \%, 9.1 \%, 9.1 \%, 7.3 \%$ and $7.3 \%$ from the dump site. All the antibiotics tested except for Gentamicin, Chloramphenicol and Ciprofloxacin differed significantly in terms of resistance levels $(\mathrm{p}<0.05)$. The study
\end{abstract}


concluded that, wastewater treatment plant and dump sites bear heavy burdens of potentially virulent resistant bacterial strains which may constitute major public health hazards to scavengers and those living near these sites. There is need therefore to educate people on the use of appropriate protective materials and the settlement patterns of individuals and communities near these sites.

\section{Keywords}

Antibiotics, Resistance, Wastewater and Solid Dump Site

\section{Introduction}

Antimicrobial resistance (AMR) has become a big threat to global health. It has risen to dangerously high levels in all parts of the world, making it difficult to treat infectious diseases [1] [2]. This is forcing patients to incur extra expenses as they have to buy more expensive second-generation or third-generation medicines. Also, as a result of medicines not being effective, patients are forced to stay longer in hospitals, this translates to higher hospital bills [3] [4]. There is a growing concern over antimicrobial resistance which is currently estimated to account for more than 700,000 deaths per year worldwide [5]. The higher rate of development of antimicrobial resistance has attracted the attention of international bodies such as WHO, FAO, OIE, who have now forged a united approach to combat it as a common force [1] [2]. If no appropriate measures are taken to halt its progress, AMR will cost approximately 10 million lives and about US $\$ 100$ trillion per year by 2050 [5]. In contrast to some other health issues, AMR is a problem that concerns every country irrespective of its level of income and development as resistant pathogens do not respect borders [5] [6].

Despite the threat presented by AMR, the 2014 World Health Organization (WHO) and the recent O'Neill report describe significant gaps in surveillance, standard methodologies and data sharing [5] [6]. The 2014 WHO report identified Africa and South East Asia as the regions which without established AMR surveillance systems [6]. This lack of quality data is problematic often leading to treatment guidelines that are not adequate for the local situation. The gap in public health capacity is also an issue given the changing resistance mechanisms and the emergence of multidrug-resistant bacteria that can only be detected through systematic screening in quality assured microbiology laboratories [7] [8].

One factor contributing to AMR is misuse of antibiotics. Improved malaria diagnostics and the recognition that malaria transmission is decreasing globally has highlighted the lack of tests for other infections and many patients who test negative for malaria are treated with antibiotics indiscriminately [9] [10] [11].

Sub-Saharan Africa (as defined by the World Bank's World Development Indicators [12] has the least comprehensive antimicrobial surveillance strategies of all world regions, alongside scarce infection prevention and control programmes. 
Only six (15\%) of the 41 WHO Africa region member states carry out surveillance for bacterial antimicrobial resistance, and external quality assurance of laboratory procedures are infrequent [13] [14] [15].

Sub-Saharan Africa has a high incidence of acute respiratory infections, diarrhoeal diseases, parasitic and invasive bacterial infections, and chronic conditions such as HIV, tuberculosis, and malnutrition [16] [17] [18] [19]. These conditions increase the demand for both preventive and therapeutic antimicrobials [20]. Unregulated antibiotics are readily available in most communities through shops and drug stores, and are widely used in domestic and commercial animal husbandry [21]. In clinics and hospitals, scarce diagnostic resources and consequent therapy based on clinical syndromes that are sensitive (rather than specific) for serious bacterial infections (therefore likely to capture viral, parasitic, and self-limiting illnesses) also drive antibiotic consumption, which is a key factor in promotion of resistance [22].

Moreover, the spread of Enterobacteriaceae that produce extended-spectrum $\beta$-lactamases (ESBLs) and other multidrug-resistant (MDR) organisms in both community-based and hospital-based populations potentially limits the availability of suitable antimicrobials to treat such infections [23] [24]. Escalation of resistance might also occur when therapies normally reserved for second-line, third-line, or fourth-line treatment in resource-rich settings (such as third-generation cephalosporins, carbapenems, and polymyxins) start to be used widely in sub-Saharan Africa without supportive microbiological facilities, expert advice, or adequate prescription controls [25] [26].

Today, antibiotics are not only used as medicine for humans but are also widely used in animal husbandry and aquaculture. However, antibiotics that are unintentionally discharged into the environment pose a great threat to ecosystems and human health [27] [28]. These antibiotics can accumulate in food webs and, even more alarming, antibiotic resistance genes (ARGs) can be transferred between environmental bacteria and human pathogens [28] [29] [30] [31]. The role of the environment as an important source and dissemination route of resistance has been increasingly recognized [32], but our understanding of its contribution is still limited. The lack of knowledge of how, and under which circumstances, the environment facilitates resistance development makes mitigation of the emergence and dissemination of mobile resistance factors problematic [33]. Several authors have highlighted the need to take on a holistic perspective on antibiotic resistance, including humans, animals and the external environment a so-called one-health approach [34] [35]. Therefore, this study sought to investigate the occurrence and concentration of antibiotics in Ruai wastewater treatment plant and Dandora dumpsite in Nairobi County, Kenya.

\section{Material and Methods}

\subsection{Study Area and Study Design}

This study was conducted in Nairobi County, Kenya. Soil and water samples were collected from Dandora dumpsites and Ruai wastewater treatment plant 
using a cross-sectional study design. The systematic sampling technique was used to collect the samples from these two study areas. The samples were collected from March to October 2018.

\subsection{Ruai Sewage Treatment Plant}

The study was carried out in Ruai Sewage Treatment Plant which is located in Nairobi East District, Embakasi Constituency. The area is $30 \mathrm{~km}$ east of Nairobi City Centre off Kangundo road (Figure 1). Its geographical coordinates are $1^{\circ} 18^{\prime} 0^{\prime \prime}$ South, $36^{\circ} 55^{\prime} 0^{\prime \prime}$ East [36]. Ruai Sewage Treatment works treat about $85,000 \mathrm{~m}^{3} /$ day equivalents to about $80 \%$ of wastewater generated from Nairobi County and handle most of industrial wastewater. The maximum capacity it can handle is $120,000 \mathrm{~m}^{3} /$ day [36], since it receives different types of wastes from Nairobi County it's known to be one the potential hotspots that could propagate and spread resistant genes to the natural environments hence there was need to determine the occurrence of resistant genes in this environment.

\subsection{Dandora Municipal Waste}

The Dandora Municipal waste dumping site is Nairobi's main (and only official) solid waste disposal site. The former quarry comprises a 30 acre expanse located to the east of Nairobi, about 8 kilometers from the city centre. Its geographical coordinates are $1^{\circ} 18^{\prime} 0^{\prime \prime}$ South, $36^{\circ} 55^{\prime} 0^{\prime \prime}$ East (Figure 2).

The City of Nairobi produces more than 3000 tonnes of waste on a daily basis. Approximately 2000 tonnes are collected and dumped at Dandora. A mix of industrial, domestic, agricultural, medical and other wastes are found scattered at the site due to the "unrestricted" dumping process. This dumping site is one of the possible pathways for propagation and distribution of resistant genes thus there was need to investigate the presence of resistant genes in this environment.

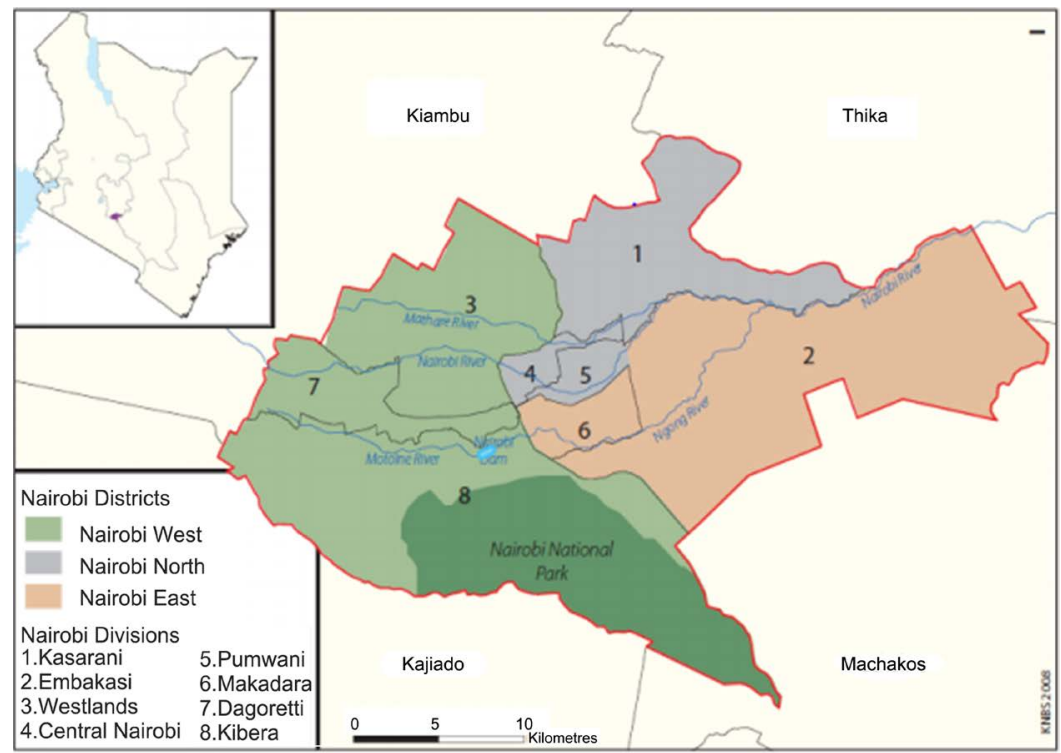

Figure 1. A map of Kenya showing Ruai Sewage Treatment Plant the study area (Nairobi River Basin Programme, Phase III). 


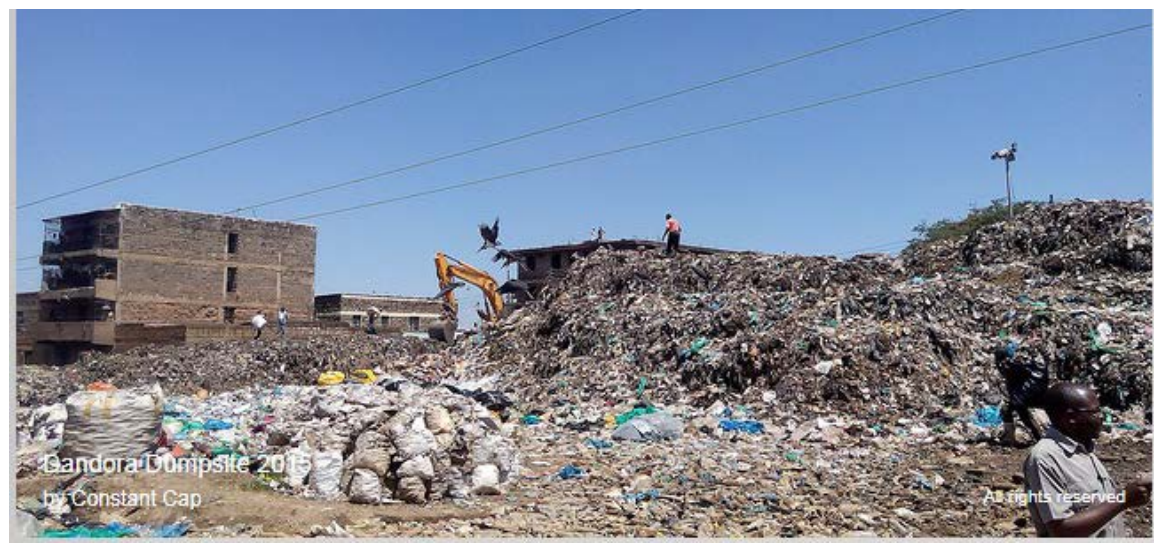

Figure 2. Dandora dumping site.

\subsection{Sample Collection and Processing}

A total of 46 samples (22 soils recovered from dumpsites and 24 wastewater recovered from wastewater treatment plant) were collected during wet (March-May, 2018) and dry (September-November, 2018) seasons. Samples were collected randomly at the study area.

Soil samples were collected $15 \mathrm{~cm}$ deep aseptically using a sterilized spatula at each point and put in sterile zip-lock plastic maintaining aseptic conditions while wastewater was collected aseptically $30 \mathrm{~cm}$ deep from ponds arranged in series i.e. 1 - 8 series using a bottle fitted with a handle then transferred to universal bottles. All the samples were transported on icebox to Microbiology laboratory for further analysis.

\subsection{Bacteria Isolation}

Bacteria were isolated by serial dilution technique on Nutrient agar media. In this technique, a sample suspension was prepared by adding $1.0 \mathrm{~g} / \mathrm{ml}$ sample (soil mixed with waste and wastewater) to $9 \mathrm{ml}$ distilled water and mixed vigorously for $5 \mathrm{~min}$. Each suspension was serially diluted and $10^{-1}$ to $10^{-5} .0 .1 \mathrm{ml}$ was pipetted onto plates with Nutrient agar media and Tryptic soy agar media (Himedia Lab. Pvt. Mumbai, India), spread with a glass spreader and incubated at $37^{\circ} \mathrm{C}$ for 24 hours. Each colony that appeared on the plate was considered as one colony forming unit [37]. Gram staining was performed to check the morphology of the cells, the bacterial isolates were biochemically characterized by TSI test, motility test, Indole test, Methyl red test, Simmon citrate test and on mannitol salt agar [38] the bacteria were classified as described by [39]. Confirmed isolates were then stored at $-80^{\circ} \mathrm{C}$ in tryptic soy broth with $10 \%$ glycerol until used in other experiments.

\subsection{Antimicrobial Susceptibility Testing}

Susceptibility tests with thirteen antibiotics were performed using the standard Kirby-Bauer disk diffusion method on Muller Hinton media (HIMedia Lab. Pvt. Mumbai, India). The antimicrobials tested were; amoxicillin (30 $\mu \mathrm{g})$, amoxiclav 
$(30 \mu \mathrm{g})$, tetracycline $(30 \mu \mathrm{g})$, chloramphenicol $(30 \mu \mathrm{g})$, gentamicin $(10 \mu \mathrm{g})$, ciprofloxacin $(30 \mu \mathrm{g})$, levofloxacin $(10 \mu \mathrm{g})$ ceftazidime $(30 \mu \mathrm{g})$, ampicillin $(10 \mu \mathrm{g})$, cefepime $(30 \mu \mathrm{g})$, cefotaxime $(30 \mu \mathrm{g})$, nitrofurantoin $(10 \mu \mathrm{g})$, imipenem $(10 \mu \mathrm{g})$, (all HIMedia Lab. Pvt. Mumbai, India). Inoculated plates were incubated at $37^{\circ} \mathrm{C}$ for 18 to $24 \mathrm{~h}$. Measurement of diameters (in millimetres) of clear zones growth inhibition, were compared with the Clinical and Laboratory Standards Institute (40) guidelines. A standard reference strain of E. coli (ATCC 35218) was used as a positive control. The breakpoints used to categorize isolates as resistant, intermediate and susceptible to each antimicrobial agent were those recommended by [40].

\subsection{Data Analysis}

Data were analyzed using the statistical package for social sciences (SPSS 15.0, IBM SPSS, New York, USA). Contingency table analysis was done by a chi-square test. A p-value of less than 0.05 was considered as statistically significant.

\subsection{Detection of Extended-Spectrum $\beta$-Lactamases (ESBLs)}

All isolates were tested for ESBLs production using the double disk synergy test following the CLSI 2017 guidelines. Only isolates that showed synergy zones between amoxicillin/clavulanic ceftazidime and cefotaxime were identified as ESBL-producers [41] [42].

Synergy between ceftazidime and clavulanate was determined by placing a disk of Augmentin ( $20 \mu \mathrm{g}$ of amoxicillin plus $10 \mu \mathrm{g}$ of clavulanic acid) and a disk of ceftazidime $30 \mathrm{~mm}$ apart (center to center). A clear-cut extension of the edge of the ceftazidime inhibition zone toward the disk containing clavulanic acid was to be interpreted as synergy, which suggests the production of ESBL. The double-disk synergy test was considered positive when decreased susceptibility to ceftazidime was combined with synergy between ceftazidime and augmentin [42].

\section{Results}

The study identified different microorganism in Ruai wastewater treatment and Dandora dumping site in Nairobi County. Out of 357 isolates recovered during the wet and dry season, 67 isolates were from Ruai wastewater treatment plant and 76 isolates were from Dandora dumping site during wet season whereas 98 isolates were recovered from Ruai wastewater treatment plant and 116 isolates from Dandora dumping site during dry season respectively (Table 1).

\subsection{Antibiotic Susceptibility Test}

Susceptibility testing was done against four broad categories of antibiotics namely beta lactams, aminoglycosides, fluoroquinolones and nucleic acid inhibitors. The diameter of the inhibition zones was measured and interpreted to resistant (R) or intermediate (I) or sensitive (S) independently according to the ClSI 2017 breakpoints for the four categories. 
Table 1. Levels (\%) of different bacteria isolates recovered from wastewater and dumpsite soils.

\begin{tabular}{|c|c|c|c|c|c|c|}
\hline \multirow[t]{2}{*}{ Bacterial isolates } & \multicolumn{3}{|c|}{$\begin{array}{l}\text { Ruai wastewater } \\
\text { treatment plant }\end{array}$} & \multicolumn{3}{|c|}{$\begin{array}{c}\text { Dandora } \\
\text { dumping site }\end{array}$} \\
\hline & $\begin{array}{c}\text { Wet } \\
(n=67)\end{array}$ & Dry (98) & $\begin{array}{c}\text { Total } \\
165\end{array}$ & $\begin{array}{c}\text { Wet } \\
(n=76)\end{array}$ & Dry (116) & $\begin{array}{c}\text { Total } \\
192\end{array}$ \\
\hline Citrobacter freundii & 2 & 3 & $5(3 \%)$ & 5 & 18 & $23(12 \%)$ \\
\hline E. coli & 11 & 12 & $23(13.9 \%)$ & 6 & 11 & $17(10.3 \%)$ \\
\hline Enterobacter aerugenes & 0 & 3 & $3(1.8 \%)$ & 2 & 0 & $2(1 \%)$ \\
\hline Klebsiella & 14 & 3 & $17(10.3 \%)$ & 7 & 9 & $16(8.3 \%)$ \\
\hline Proteus vulgaris & 12 & 0 & $12(7.2 \%)$ & 1 & 0 & $1(0.5 \%)$ \\
\hline Pseudomonas & 9 & 1 & $10(6 \%)$ & 15 & 6 & $21(11 \%)$ \\
\hline Serratia & 4 & 7 & $11(6.7 \%)$ & 11 & 16 & $27(14.1 \%)$ \\
\hline Shigella & 3 & 32 & $35(21.2 \%)$ & 16 & 13 & $29(15.1 \%)$ \\
\hline Staphylococcus & 3 & 4 & $7(4.2 \%)$ & 11 & 9 & $20(10.4 \%)$ \\
\hline Bacillus & 0 & 0 & $0 \%$ & 1 & 0 & $1(0.5 \%)$ \\
\hline Salmonella & 9 & 2 & $11(6.7 \%)$ & 1 & 0 & $1(0.5 \%)$ \\
\hline Proteus mirabilis & 0 & 5 & $5(3 \%)$ & 0 & 0 & $0 \%$ \\
\hline Citrobacter koseri & 0 & 7 & $7(4.2 \%)$ & 0 & 4 & $4(2.1 \%)$ \\
\hline Vibrio cholera & 0 & 1 & $1(0.6 \%)$ & 0 & 3 & $3(1.6 \%)$ \\
\hline Providencia & 0 & 8 & $8(4.8 \%)$ & 0 & 4 & $4(2.1 \%)$ \\
\hline Yersinia & 0 & 2 & $2(1.2 \%)$ & 0 & 3 & $3(1.6 \%)$ \\
\hline Morganella & 0 & 2 & $2(1.2 \%)$ & 0 & 1 & $1(0.5 \%)$ \\
\hline Citrobacter cloacoe & 0 & 0 & $0 \%$ & 0 & 2 & $2(1.0 \%)$ \\
\hline
\end{tabular}

In this study, 13 different types of antibiotic were used to test susceptibility. Different rates of resistance level were recorded to various isolates recovered from Ruai wastewater treatment plant and Dandora dumping site during wet and dry season as shown in (Figure 3 and Figure 4).

\subsection{Extended Spectrum Beta Lactamases}

Out of 357 bacterial isolates, there was a high prevalence of ESBL producers across wastewater and dumping site as shown in (Figure 5 and Figure 6)

\section{Discussions}

The recovery of members of genera Escherichia, Enterobacter, Klebsiella, Citrobacter, Proteus, Shigella and Serratia directly points to these sites as high risk [42], and therefore sites investigated in this study may pose a public health risk if not put under appropriate management. These results are in agreement to those published in a related study conducted in Kenya among various wastewater treatment plants, dumpsites and garbages [42]. The presence of these microbes 


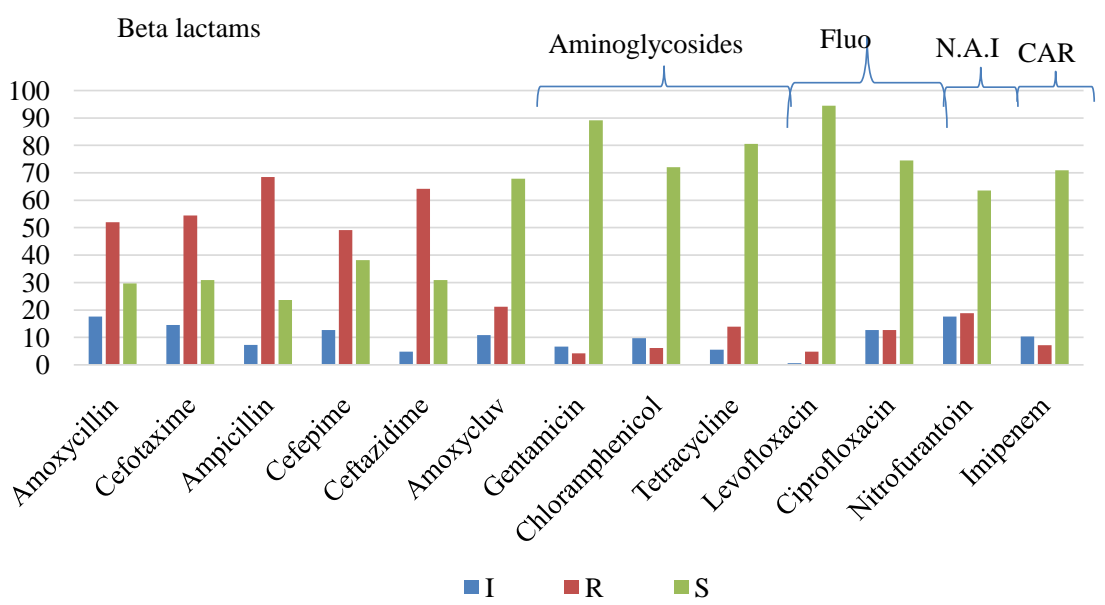

Figure 3. The percentage of susceptibility of the bacterial isolates from Ruai wastewater treatment plant. Key: Fluo-Flouroquinolones; N.A.I-Nucleic acid inhibitors; CAR-Carbapenem.

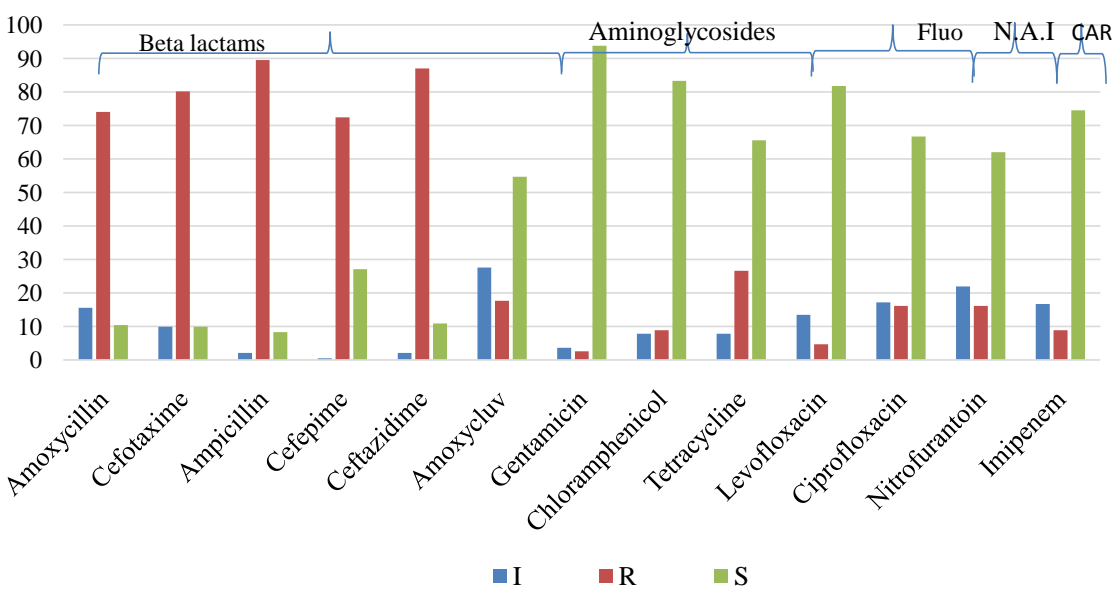

Figure 4. The percentage of susceptibility of the bacterial isolates from Dandora dumping site. Key: Fluo-Flouroquinolones; N.A.I-Nucleic acid inhibitors; CAR-Carbapenem.

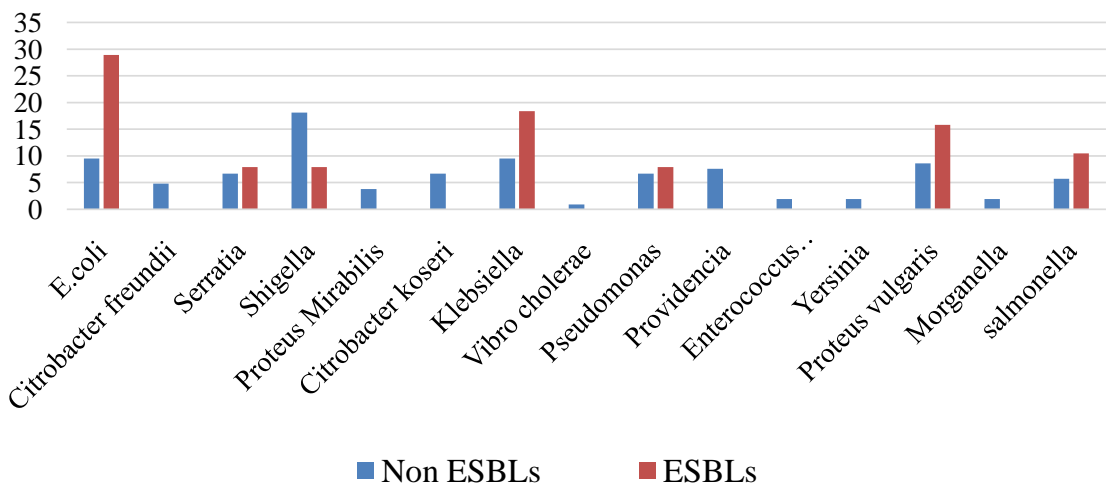

Figure 5. The percentage of ESBLs bacterial isolates producers from Ruai wastewater treatment plant.

in dumpsites has previously been shown to demonstrate the accumulation of unsorted garbage. According to [43] such dumpsites have shown to possess a 


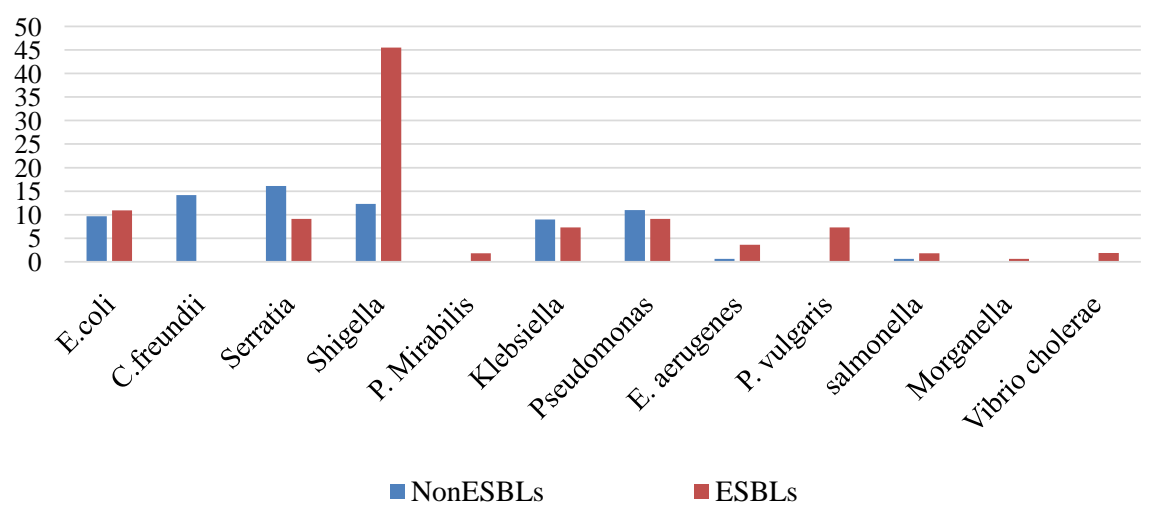

Figure 6. The percentage of ESBLs bacterial isolates producers from Dandora dumping site.

variety of wastes ranging from domestic, biomedical and industrial wastes, a fact which was also observed at the dumpsite investigated in this study. The results obtained in this study correlates with that of [44] which showed that the mean total bacterial counts obtained from the dumpsite area relatively higher. Dandora dumpsite is the largest dumpsite in East and Central Africa, where wastes from different parts of Nairobi is dumped. This potentially offers a chance of transfer of pathogens from such sites to human residential sites since Dandora dumpsite is closely located to an ever busy residential area and can be easily accessed by all kinds of people and animals.

Some of the isolates recovered are potential pathogens that have been incriminated with various human diseases. The presence of some of these organisms on the dumpsite and garbage areas is alarming as those working and living at the dumpsites could serve as reservoirs for potential contamination of other close contacts. These results are in agreement with a study done in Nigeria that found that waste scavenging poses a great threat to the public. In addition, such dumpsites allow the growth of many pathogenic bacteria including those that may be multi drug resistant [45]. Human and animal scavengers were invariably at the site at all times.

The presence of these isolates in leachates at the dumpsites is also a major public health threat as leachates may seep into nearby surface or underground potable waters. Besides health care settings, the environment is likely to have a role in the dissemination of ESBL-producing bacteria and may serve as an exposure route to humans. Previously recreational waters were identified as a potential exposure source of ESBL-producing E. coli. Even though (outside the clinical setting) $E$. coli is generally considered a relatively harmless inhabitant of the human (and animal) gut, major public health risks may be associated with the spread of ESBL-producing commensal bacteria [46].

High proportion of resistant isolates was observed in this study, Ampicillin, Ceftazidime, Cefotaxime, Amoxicillin and Cefepime recorded the highest level of inactivity at $(68.5 \%, 89.5 \%),(64.2 \%, 87 \%),(54.5 \%, 80.2 \%),(52 \%, 74 \%)$ and $(49.1 \%, 72.4 \%)$ while Levofloxacin and Gentamicin showed the smallest level of 
antibiotic resistance at $(4.8 \%, 4.7 \%)$ and $(4.2 \%, 2.6 \%)$ in both sites (Ruai wastewater treatment plant and Dandora dumping site). The resistance level differed slightly in percentage with isolates recovered from the study sites during wet and dry season (Figure 3 and Figure 4). High resistant to antibiotics was observed at Dandora dumping site as compared to Ruai wastewater treatment plant. While this values may be higher than those reported from garbage and dumpsite studies in selected sites in Nairobi County, these results suggest that resistance to antimicrobials is rising and this may be due to either the intrinsic resistance of many microorganisms to antibiotics or acquired resistance of the organisms enabled by the transfer of resistance of drug resistance plasmids [47]. A high level of resistance has been found with members of the family Enterobacteriaceae which are increasingly becoming multi drug resistant. The origin of this resistance can probably be traced to the fecal constituent of the wastes or dump produced by people or animals that have been treated indiscriminately with various antibiotics and also to antibiotics production naturally by soil microorganisms [47].

There was high resistance to beta lactams from wastewater treatment plant and dumping site during both seasons in this study. Beta lactams are of great importance in the public health sector and as first line therapy for a wide variety of infections, hence its continued relevance and usage [48]. Most bacteria of clinical importance have become resistant to the antimicrobials found in this group, thus posing great danger to the sector. Based on the susceptibility patterns observed among our isolates towards beta lactams, these antimicrobials are likely to remain potent for a long time against bacteria of environmental origin.

Among aminoglycosides, Gentamicin and Chloraphenicol were more potent than Tetracycline because there was low of resistance to bacterial isolates where Gentamicin recorded $(4.2 \%, 2.6 \%)$ and Chloramphenicol recorded $(6.6 \%, 8.9 \%)$ from wastewater and dumping site compared to $(13.9 \%, 26.6 \%)$ for Tetracycline respectively. This observation of chloramphenicol being more effective than tetracycline is similar to findings of a study that attempted to evaluate the use of old antibiotic compounds in treatment of biofilm forming multidrug resistant organisms [49]. Aminoglycosides are an important class of antimicrobials that may be used together with $\beta$-lactams and also with fluoroquinolones against invasive strains. Most aminoglycosides are administered through injections and may, therefore, be protected against the degradative effect of the gastrointestinal tract as is common with other antimicrobials administered orally. Due to their mode of administration, it is more unlikely that this class of antimicrobials are misused and are therefore more amenable for treatment of hospitalized patients especially those in intensive care unit.

Moreover, among the quinolones, resistance to Levofloxacin was low $4.8 \%$, $4.7 \%)$ compared to $(12.7 \%, 16.1 \%)$ for Ciprofloxacin. Based on these results it is evident that Levofloxacin, Gentamicin and Chloramphenicol are still potent antimicrobials as replacer antimicrobials for treatment of infections caused by ESBL producers and the majority of multi drug resistance strains. The apparent 
increase in fluoroquinolone-resistant strains in Kenya and the world could be attributed to its wide use of these antimicrobials against ESBL-producers and in the treatment of UTIs and respiratory infections. Other studies have hinted that overuse of fluoroquinolones in human and veterinary medicine could also breed resistance [50]. Another 21.2\%, 17.7\% of isolates were also resistant to Amoxicillin-Clavulanic acid (a $\beta$-lactamase inhibitor) heavily relied upon for treatment of ESBL-producers. Nitrofurantoin and imipenem showed moderate activity against bacteria species. Similar findings have been reported in other clinical studies in Kenya, Tanzania, and Iran [51] [52] [53]. In these three studies, imipenem was shown to be the most active antibiotic against ESBL producing isolates and nitrofurantoin showed moderate activity.

Based on the resistance profiles of the isolates obtained from the two study areas, $28.9 \%$ of E. coli, $18.4 \%$ of Klebsiella, $15.8 \%$ of Proteus vulgaris, $10.5 \%$ of Salmonella and $7.9 \%$ of Pseudomonas, Shigella and Serratia isolates were the highly ESBL-producers in wastewater treatment. Shigella was the highest ESBL-producer in dumping site at $45 \%$, followed by E.coli at $10.9 \%$, Serratia, Pseudomonas at 9.1\%, Klebsiella and Proteus vulgaris at 7.3\% respectively. These observations are in contrast to those made on isolates from clinical backgrounds [54] that suggest the apparent rise of ESBLs. other studies by [54] [55] [56] reported a high prevalence of ESBL-producing E. coli among healthy individuals in Southeast Asia, including China (65.0\%) and a range of between $58.2 \%-69.3 \%$ in Thailand (56), 51\% in Vietnam [57] and also among healthy tourists traveling from Netherlands to East and South Asia [58]. This global increase in the prevalence of ESBL-producing strains is particularly worrisome and this situation might be accelerated by globalization, tourism and/or migration of individuals who are likely to aid in the spread of these resistant strains worldwide making the containment of such strains difficult especially in hospital and community settings.

All the antibiotics tested except for Gentamicin, Chloramphenicol and Ciprofloxacin differed significantly in terms of resistance levels $(\mathrm{p}<0.05)$, it indicate that the resistance genes in the wastewater treatment and dumpsite sites may be closely associated and probably common to mobile genetic elements that are circulating and evolving, calling for more investigations. This study supports the hypothesis that natural environment such as wastewater treatment and dumping sites can act as reservoirs for emerging microbial contaminants including antibiotic resistance genes.

\section{Conclusions}

Antibiotic resistance amongst wastewater bacterial species is a serious threat in Kenya. Continuous and close monitoring of antibiotic resistance among bacteria associated with waste treatment sites, to understand emerging antibiotic resistance patterns at these sites, form an important interphase for microbes originating from humans and the environment. Poor waste disposal and recycling 
practices are still rampant across the dumpsites and garbage collection areas.

Isolates from dumpsite collection area were resistant to a high proportion of the antimicrobials. This shows that clinical bacterial strains are gaining access into the environment thus the high resistance prevalence. From the study, there was a high occurrence of Shigella, Escherichia coli, Klebsiella, Pseudomonas, Proteus vulgaris, Citrobacterfreundii, Serratia and Salmonella across the dumpsite indicating environmental contamination. The most effective antimicrobial was chloramphenicol, gentamicin and levofloxacin to both strains. The most non-effective antimicrobial was ampicillin, amoxicillin, cefotaxime, cefepime and ceftazidime indicating that the future of the antimicrobials is at risk with the changing bacterial pressure.

\section{Recommendations}

The county governments' needs to institute proper training of safe practices when handling garbage to those collecting the garbage in order to reduce the spread of multi drug resistant bacteria and genes.

Government should control the settlement patterns of individuals and communities and ensure that residentials are far removed from dumpsites and wastewater treatment plant.

Further surveillance studies on the effectiveness of non-effective antimicrobials should be done to conclusively determine their future with the changing bacterial pressures.

\section{Acknowledgements}

We would like to express our sincere appreciation to the staff members of Medical Microbiology department (J.K.U.A.T) for allowing us to work in the laboratory, not forgetting Mr. Rodgers and Mr. Owaga for helping in availing sampling opportunities. We also thank Pan Africa University Institute for Basic Science Innovation and Technology and Mawazo Institute for Women Leading Research in Africa for the research grants without which it would have been impossible to do this work. The financial support is highly acknowledged.

\section{Conflicts of Interest}

The authors declare no conflicts of interest regarding the publication of this paper.

\section{References}

[1] Maron, D.F. (2016) Superbug Explosion Triggers UN General Assembly (UNGA) meeting. Scientific America.

[2] Perovic, O. and Schultz, C. (2016) Stepwise Approach for Implementation of Antimicrobial Resistance Surveillance in Africa. African Journal of Laboratory Medicine, 5, 482-488. https://doi.org/10.4102/ajlm.v5i3.482

[3] OIE (2015) Fact Sheet on Antimicrobial Resistance. 
[4] WHO (2015) Global Action Plan on Antimicrobial Resistance.

[5] O’Neill, J. (2016) Tackling Drug-Resistant Infections Globally: Final Report and Recommendations. http://amr-review.org/sites/default/files/160525 Final\%20paper with\%20cover.pdf

[6] WHO (2014) Antimicrobial Resistance. In: Global Report on Surveillance, Geneva, Switzerland.

[7] Liu, Y.Y., Wang, Y., Walsh, T.R., Yi, L.X., Zhang, R., Spencer, J., Doi, Y., Tian, G., Dong, B., Huang, X., et al. (2016) Emergence of Plasmid-Mediated Colistin Resistance Mechanism MCR-1 in Animals and Human Beings in China: A Microbiological and Molecular Biological Study. The Lancet Infectious Diseases, 16, 161-168. https://doi.org/10.1016/S1473-3099(15)00424-7

[8] Xavier, B.B., Lammens, C., Ruhal, R., Kumar-Singh, S., Butaye, P., Goossens, H. and Malhotra-Kumar, S. (2016) Identification of a Novel Plasmid-Mediated ColistinResistance Gene, mcr-2, in Escherichia coli, Belgium, June 2016. Eurosurveillance, 21, pii=30280. https://doi.org/10.2807/1560-7917.ES.2016.21.27.30280

[9] WHO (2015) World Malaria Report. WHO, Switzerland, Geneva. http://apps.who.int/iris/bitstream/10665/200018/1/9789241565158 eng.pdf?ua=1.

[10] Harbarth, S. and Samore, M.H. (2005) Antimicrobial Resistance Determinants and Future Control. Emerging Infectious Diseases, 11, 794-801. https://doi.org/10.3201/eid1106.050167

[11] Do, N.T., Ta, N.T., Tran, N.T., Than, H.M., Vu, B.T., Hoang, L.B., van Doorn, H.R., Vu, D.T., Cals, J.W., Chandna, A., et al. (2016) Point-of-Care C-Reactive Protein Testing to Reduce Inappropriate Use of Antibiotics for Non-Severe Acute Respiratory Infections in Vietnamese Primary Health Care: A Randomised Controlled Trial. The Lancet Global Health, 4, E633-E641. https://doi.org/10.1016/S2214-109X(16)30142-5

[12] The World Bank (2015) World Development Indicators. http://databank.worldbank.org/data/reports.aspx?source=2\&country=SSF

[13] Ashley, E., Lubell, Y., White, N. and Turner, P. (2011) Antimicrobial Susceptibility of Bacterial Isolates from Community-Acquired Infections in Sub-Saharan Africa and Asian Low and Middle Income Countries. Tropical Medicine \& International Health, 16, 1167-1179. https://doi.org/10.1111/j.1365-3156.2011.02822.x

[14] Leopold, S., ven Leth, F., Terekegn, H. and Schultsz, C. (2014) Antimicrobial Drug Resistance among Clinically Relevant Bacterial Isolates in Sub-Saharan Africa: A Systematic Review. Journal of Antimicrobial Chemotherapy, 69, 2337-2353. https://doi.org/10.1093/jac/dku176

[15] WHO (2015) Worldwide Country Situation Analysis: Response to Antimicrobial Resistance. World Health Organization, Geneva.

[16] Bahwere, P., Levy, J., Hennart, P., et al. (2001) Community-Acquired Bacteraemia among Hospitalized Children in Rural Central Africa. International Journal of Infectious Diseases, 5, 180-188.

[17] Reddy, E., Shaw, A.V. and Crump, J.A. (2010) Community-Acquired Bloodstream Infections in Africa: A Systematic Review and Meta-Analysis. The Lancet Infectious Diseases, 10, 417-432. https://doi.org/10.1016/S1473-3099(10)70072-4

[18] Seale, A., Davies, M., Anampiu, K., et al. (2016) Invasive Group A Streptococcus Infection among Children, Rural Kenya. Emerging Infectious Diseases, 22, 224-232. https://doi.org/10.3201/eid2202.151358

[19] Kissoon, N. and Uyeki, T. (2016) Sepsis and the Global Burden of Disease in Children. JAMA Pediatrics, 170, 107-108. 
https://doi.org/10.1001/jamapediatrics.2015.3241

[20] Omulo, S., Thumbi, S.M., Njenga, M.K. and Call, D.R. (2015) A Review of 40 Years of Enteric Antimicrobial Resistance Research in Eastern Africa: What Can Be Done Better? Antimicrobial Resistance \& Infection Control, 4, 1. https://doi.org/10.1186/s13756-014-0041-4

[21] Eager, H., Swan, G. and van Vuuren, M. (2012) A Survey of Antimicrobial Usage in Animals in South Africa with Specific Reference to Food Animals. Journal of the South African Veterinary Association, 83, No. 1. https://doi.org/10.4102/jsava.v83i1.16

[22] Blomberg, B., Manji, K., Urassam, W., et al. (2007) Antimicrobial Resistance Predicts Death in Tanzanian Children with Bloodstream Infections: A Prospective Cohort Study. BMC Infectious Diseases, 22, 43.

https://doi.org/10.1186/1471-2334-7-43

[23] Storberg, V. (2014) ESBL-Producing Enterobacteriaceae in Africa-A Non-Systematic Literature Review of Research Published 2008-2012. Infection Ecology \& Epidemiology, 4, Article ID: 20342. https://doi.org/10.3402/iee.v4.20342

[24] Pitout, J.D. and Laupland, K.B. (2008) Extended-Spectrum $\beta$-Lactamase-Producing Enterobacteriaceae: An Emerging Public-Health Concern. The Lancet Infectious Diseases, 8, 159-166. https://doi.org/10.1016/S1473-3099(08)70041-0

[25] Murunga, E.M., Reriani, M., Otieno, C.F. and Wanyoike, N.M. (2005) Comparison of Antibiotic Use between an 'Open' and a 'Closed' Intensive Care Unit. East African Medical Journal, 82, 414-417. https://doi.org/10.4314/eamj.v82i8.9326

[26] Versporten, A., Bielicki, J., Drapier, N., Sharland, M., Goossens, H., et al. (2016) The Worldwide Antibiotic Resistance and Prescribing in European Children (ARPEC) Point Prevalence Survey: Developing Hospital-Quality Indicators of Antibiotic Prescribing for Children. Journal of Antimicrobial Chemotherapy, 71, 1106-1117. https://doi.org/10.1093/jac/dkv418

[27] Yang, Y., Xu, C., Cao, X., Lin, H. and Wang, J. (2017) Antibiotic Resistance Genes in Surface Water of Eutrophic Urban Lakes Are Related to Heavy Metals, Antibiotics, Lake Morphology and Anthropic Impact. Ecotoxicology, 26, 831-840. https://doi.org/10.1007/s10646-017-1814-3

[28] Bengtsson-Palme, J. and Larsson, D.G.J. (2015) Antibiotic Resistance Genes in the Environment: Prioritizing Risks. Nature Reviews Microbiology, 13, 396. https://doi.org/10.1038/nrmicro3399-c1

[29] Li, B., Yang, Y., Ma, L., Ju, F., Guo, F., Tiedje, J.M. and Zhang, T. (2015) Metagenomic and Network Analysis Reveal Wide Distribution and Co-Occurrence of Environmental Anti-Biotic Resistance Genes. The ISME Journal, 9, 2490-2502. https://doi.org/10.1038/ismej.2015.59

[30] Martinez, J.L., Coque, T.M. and Baquero, F. (2015) What Is a Resistance Gene? Ranking Risk in Resistomes. Nature Reviews Microbiology, 13, 116-123. https://doi.org/10.1038/nrmicro3399

[31] Van Boeckel, T.P., Brower, C., Gilbert, M., Grenfell, B.T., Levin, S.A., Robinson, T.P., Teillant, A. and Laxminarayan, R. (2015) Global Trends in Antimicrobial Use in Food Animals. Proceedings of the National Academy of Sciences of the United States of America, 112, 5649-5654. https://doi.org/10.1073/pnas.1503141112

[32] Bondarczuk, K., Markowicz, A. and Piotrowska-Seget, Z. (2015) The Urgent Need for Risk Assessment on the Antibiotic Resistance Spread via Sewage Sludge Land Application. Environment International, 87, 49-55.

https://doi.org/10.1016/j.envint.2015.11.011 
[33] Berendonk, T.U., Manaia, C.M., Merlin, C., et al. (2015) Tackling Antibiotic Resistance: The Environmental Framework. Nature Reviews Microbiology, 13, 310-317. https://doi.org/10.1038/nrmicro3439

[34] Collignon, P. (2013) Ban Routine Use of Critically Important Antibiotics in Food Animals. BMJ, 347, f4976. https://doi.org/10.1136/bmj.f4976

[35] So, A.D., Shah, T.A., Roach, S., et al. (2015) An Integrated Systems Approach Is Needed to Ensure the Sustainability of Antibiotic Effectiveness for Both Humans and Animals. The Journal of Law, Medicine \& Ethics, 43, 38-45. https://doi.org/10.1111/jlme.12273

[36] Opijah, F.J., Mukabana, J.R. and Ng'ang'a, J.K. (2007) Rainfall Distribution over Nairobi Area. Journal of Meteorological Research, 1, 3-13.

[37] Nazir, N., Mirza, J.H., Akhtar, N., Bajwa, R. and Nasin, G. (2007) Some Studies of Thermophilic and Thermotolerant Fungi from Lahore, Pakistan. Mycopathologia, 5, 95-100.

[38] Zaved, H.K., Rahman Mizanur, M., Rahman Mashir, M., Rahman, A., Arafat, S.M.Y. and Rahman, M.S. (2008) Isolation and Characterization of Effective Bacteria for Solid Waste Degradation for Organic Manure. KMITL Science and Technology Journal, 8, 44-55.

[39] Cheesbrough, M. (2006) District Laboratory Practice in Tropical Countries. Part 2. Cambridge University Press, Cambridge. https://doi.org/10.1017/CBO9780511543470

[40] Clinical and Laboratory Standards Institute (2017) Performance Standards for Antimicrobial Susceptibility Testing. 27th Edition.

[41] Rawat, D. and Nair, D. (2010) Extended-Spectrum $\beta$-Lactamases in Gram Negative Bacteria. Journal of Global Infectious Diseases, 2, 263-274. https://doi.org/10.4103/0974-777X.68531

[42] Jarlier, V., Nicolas, M.H., Fournier, G. and Philippon, A. (1988) Extended Broad-Spectrum Beta-Lactamases Conferring Transferable Resistance to Newer Beta-Lactam Agents in Enterobacteriaceae: Hospital Prevalence and Susceptibility Patterns. Reviews of Infectious Diseases, 10, 867-878.

https://doi.org/10.1093/clinids/10.4.867

[43] Clarice, M., Anthony, S. and Shivoga, W.A. (2018) Antimicrobial Resistance Patterns of Enterobacteriaceae Recovered from Wastewater, Sludge and Dumpsite Environments in Kakamega Town, Kenya. African Journal of Microbiology Research, 12, 673-680.

[44] Mwaikono, K.S., Maina, S. and Gwakisa, P. (2015) Prevalence and Antimicrobial Resistance Phenotype of Enteric Bacteria from a Municipal Dumpsite. Journal of Applied and Environmental Microbiology, 3, 82-94.

[45] Odeyemi, A. (2012) Antibiogram Status of Bacterial Isolates from Air around Dumpsite of Ekiti State Destitute Centre at Ilokun, Ado-Ekiti, Nigeria. Journal of Microbiology Research, 2, 12-18. https://doi.org/10.5923/j.microbiology.20120202.03

[46] Wachukwu, C.K., Mbata, C.A. and Nyenke, C.U. (2010) The Health Profile and impact Assessment of Waste Scavengers (Rag Pickers) in Port Harcourt, Nigeria. Journal of Applied Sciences, 10, 1968-1972. https://doi.org/10.3923/jas.2010.1968.1972

[47] Liu, H., Wang, Y., Wang, G., Xing, Q., Shao, L., Dong, X., Ma, L., et al. (2015) The Prevalence of Escherichia coli Strains with Extended Spectrum Beta-Lactamases 
Isolated in China. Frontiers in Microbiology, 6, 1-5.

[48] Njoroge, S. (2015) Phenotypic and Genotypic Resistance Patterns among Fecal E. coli Isolated from Severely Malnourished and Non-Malnourished Children Attending Mbagathi District Hospital, Nairobi. Master's Thesis, Kenyatta University, Kahawa.

[49] Tenover, F.C. (2006) Mechanisms of Antimicrobial Resistance in Bacteria. American Journal of Infection Control, 34, S3-S10. https://doi.org/10.1016/j.ajic.2006.05.219

[50] Webber, M. and Piddock, L.J. (2001) Quinolone Resistance in Escherichia coli. Veterinary Research, 32, 275-284.

[51] Daniel, M., Makau, P., Nyerereand, A. and Revathi, G. (2017) Antimicrobial Resistance patterns in Extended-Spectrum $\beta$-Lactamase Producing Escherichia coli and Klebsiella pneumonia Isolates in a Private Tertiary Hospital, Kenya. Microbiology Discovery, 1, 1-5.

[52] Mehrgan, H., Rahbar, M. and Arab-Halvaii, Z. (2010) High Prevalence of ExtendedSpectrum Beta-Lactamase-Producing Klebsiella pneumoniae in a Tertiary Care Hospital in Tehran, Iran. The Journal of Infection in Developing Countries, 4, 132-138. https://doi.org/10.3855/jidc.488

[53] Moyo, S.J., Aboud, S., Kasubi, M., Lyamuya, E.F. and Maselle, S.Y. (2010) Antimicrobial Resistance among Producers and Non-Producers of Extended Spectrum Beta-Lactamases in Urinary Isolates at a Tertiary Hospital in Tanzania. BMC Res Notes, 3, 348. https://doi.org/10.1186/1756-0500-3-348

[54] Kiiru, J., Kariuki, S., Goddeeris, B.M. and Butaye, P. (2012) Analysis of Beta-Lactamase Phenotypes and Carriage of Selected Beta-Lactamase Genes among Escherichia coli Strains Obtained from Kenyan Patients during an 18-Year Period. BMC Microbiology, 12, 155. https://doi.org/10.1186/1471-2180-12-155

[55] Nakane, K., Kawamura, K., Goto, K. and Arakawa, Y. (2016) Long-Term Colonization by blaстх-м-Harboring Escherichia coli in Healthy Japanese People Engaged in Food Handling. Applied and Environmental Microbiology, 82, 1818-1827. https://doi.org/10.1128/AEM.02929-15

[56] Zhang, H., Zhou, Y., Guo, S. and Chang, W. (2015) High Prevalence and Risk Factors of Fecal Carriage of CTX-M Type Extended-Spectrum Beta-Lactamase-Producing Enterobacteriaceae from Healthy Rural Residents of Taian, China. Frontiers in Microbiology, 6, 239. https://doi.org/10.3389/fmicb.2015.00239

[57] Le, Q.P., Ueda, S., Nguyen, T.N.H., Dao, T.V.K., Van Hoang, T.A., Tran, T.T.N., Vien, Q.M., et al. (2015) Characteristics of Extended-Spectrum $\beta$-Lactamase-Producing Escherichia coli in Retail Meats and Shrimp at a Local Market in Vietnam. Foodborne Pathogens and Disease, 12, 719-725.

https://doi.org/10.1089/fpd.2015.1954

[58] Paltansing, S., Vlot, J.A., Kraakman, M.E., Mesman, R., Bruijning, M.L., Bernards, A.T. and Veldkamp, K.E. (2013) Extended-Spectrum $\beta$-Lactamase-Producing Enterobacteriaceae among Travelers from the Netherlands. Emerging Infectious Diseases, 19, 1206-1213. https://doi.org/10.3201/eid1908.130257 